\title{
A simple formula for calculating porosity of magma in volcanic conduits during dome-forming eruptions
}

\author{
Tomofumi Kozono $^{1}$ and Takehiro Koyaguchi ${ }^{2}$ \\ ${ }^{1}$ National Research Institute for Earth Science and Disaster Prevention, 3-1, Tennodai, Tsukuba, Ibaraki 305-0006, Japan \\ ${ }^{2}$ Earthquake Research Institute, University of Tokyo, 1-1-1, Yayoi, Bunkyo-ku, Tokyo 113-0032, Japan
}

(Received December 14, 2009; Revised February 12, 2010; Accepted February 15, 2010; Online published July 9, 2010)

\begin{abstract}
We present a simple formula for analyzing factors that govern porosity of magma in dome-forming eruptions. The formula is based on a 1-dimensional steady conduit flow model with vertical gas escape, and provides the value of the porosity as a function of magma flow rate, magma properties (viscosity and permeability), and pressure. The porosity for a given pressure depends on two non-dimensional numbers $\varepsilon$ and $\theta$. The parameter $\varepsilon$ represents the ratio of wall friction force to liquid-gas interaction force, and is proportional to the magma viscosity. The parameter $\theta$ represents the ratio of gravitational load to liquid-gas interaction force and is inversely proportional to the magma flow rate. Gas escape is promoted and porosity decreases with increasing $\varepsilon$ or $\theta$. From the possible ranges of $\varepsilon$ and $\theta$ for typical magmatic conditions, it is inferred that the porosity is primarily determined by $\varepsilon$ at the atmospheric pressure (near the surface), and by $\theta$ at higher pressures (in the subsurface region inside the conduit). The porosity near the surface approaches 0 owing to high magma viscosity regardless of the magnitude of the magma flow rate, whereas the subsurface porosity increases to more than 0.5 with increasing magma flow rate.
\end{abstract}

Key words: Conduit flow, dome-forming eruptions, magma porosity, gas escape from magma.

\section{Introduction}

As silicic volatile-rich magma ascends to the surface and decompresses in volcanic conduits, the magma vesiculates and its porosity (i.e., gas volume fraction) increases. The porosity changes with depth owing to the competition between the vesiculation and escape of gas from the magma. When gas escape occurs efficiently, the porosity decreases, which may lead to an effusion of a lava dome with a low porosity (Eichelberger et al., 1986; Jaupart and Allegre, 1991; Woods and Koyaguchi, 1994). Recent numerical studies have revealed that the porosity critically depends on magma properties such as viscosity and permeability in dome-forming eruptions and that complex porosity profiles may result as viscosity, permeability, or both change with depth; the porosity increases in the subsurface region, and then decreases near the surface (e.g., Melnik and Sparks, 1999; Diller et al., 2006). However, the relationships between porosity and viscosity and between porosity and permeability are still unclear, which makes it difficult to understand the mechanism through which the complex porosity profiles are formed.

In this study, we derive a simple formula for calculating the porosity in dome-forming eruptions as a function of the magma properties and geological conditions. This formula is based on a 1-dimensional steady conduit flow model that considers vertical gas escape from magma. This for-

Copyright (C) The Society of Geomagnetism and Earth, Planetary and Space Sciences (SGEPSS); The Seismological Society of Japan; The Volcanological Society of Japan; The Geodetic Society of Japan; The Japanese Society for Planetary Sciences; TERRAPUB.

doi:10.5047/eps.2010.02.005 mula enables us to systematically investigate how porosity changes in response to changes in viscosity and permeability during magma ascent and also to identify the essential effects controlling the porosity profile in the conduit.

\section{A Formula for Calculating Porosity}

Here, we consider a 1-dimensional steady flow through a cylindrical conduit with a constant radius where the vertical relative motion between the gas and the liquid phases (i.e., vertical gas escape) is taken into account (Kozono and Koyaguchi, 2009a). As the magma ascends from depth, volatiles exsolve and bubbles are nucleated, and the flow takes a form in which bubbles are suspended in a continuous liquid phase (bubbly flow). As the magma ascends further, bubbles connect and paths for gas flow are formed. The flow takes a form in which both the gas and the liquid are continuous phases, which results in efficient vertical gas escape as permeable flow (Fig. 1).

The basic equations for the above model are expressed by

$$
\begin{gathered}
\rho_{\mathrm{l}} u_{\mathrm{l}}(1-\phi)=(1-n) q, \\
\rho_{\mathrm{g}} u_{\mathrm{g}} \phi=n q, \\
\rho_{\mathrm{l}} u_{\mathrm{l}}(1-\phi) \frac{\mathrm{d} u_{\mathrm{l}}}{\mathrm{d} z}=-(1-\phi) \frac{\mathrm{d} P}{\mathrm{~d} z}-\rho_{\mathrm{l}}(1-\phi) g+F_{\mathrm{lg}}-F_{\mathrm{lw}}, \\
\rho_{\mathrm{g}} u_{\mathrm{g}} \phi \frac{\mathrm{d} u_{\mathrm{g}}}{\mathrm{d} z}=-\phi \frac{\mathrm{d} P}{\mathrm{~d} z}-\rho_{\mathrm{g}} \phi g-F_{\mathrm{lg}}, \\
P=\rho_{\mathrm{g}} R T,
\end{gathered}
$$

and

$$
n=\frac{n_{0}-s P^{1 / 2}}{1-s P^{1 / 2}} \quad(n \geq 0),
$$




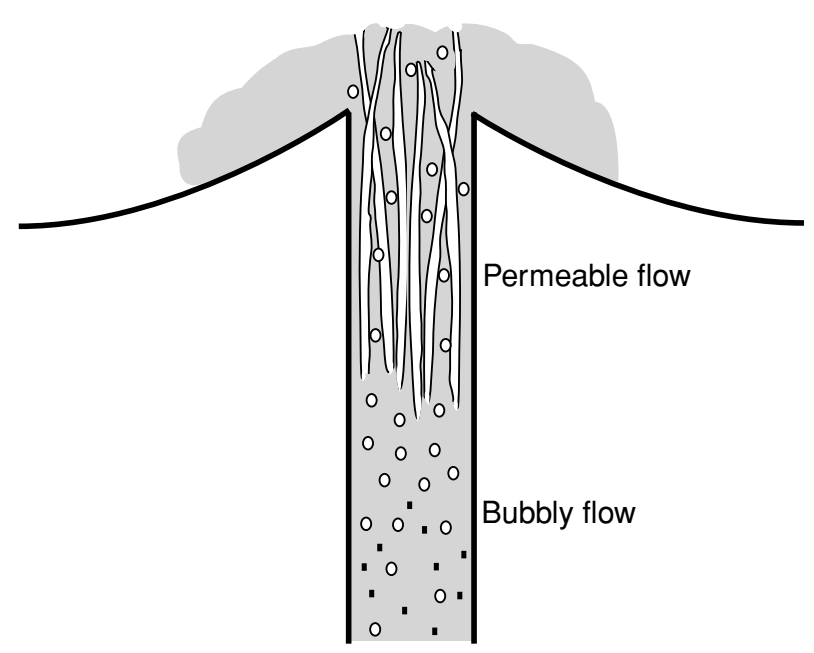

Fig. 1. Schematic illustration of flow style in a conduit during dome-forming eruptions assumed in this study. The flow style changes from bubbly to permeable flow during magma ascent. See text for detail.

where $u_{1}$ and $u_{\mathrm{g}}$ are the vertical velocities of the liquid and the gas respectively, $\rho_{\mathrm{l}}\left(=2500 \mathrm{~kg} \mathrm{~m}^{-3}\right)$ and $\rho_{\mathrm{g}}$ are the densities of the liquid and the gas respectively, $\phi$ is the gas volume fraction (i.e., the porosity), $n$ is the gas mass-flow-rate fraction, $q$ is the mass flow rate (per unit of cross-section area; $\mathrm{kg} \mathrm{m}^{-2} \mathrm{~s}^{-1}$ ), $z$ is the vertical coordinate measured positive upwards, $P$ is the pressure of the magma, $g$ is the acceleration due to gravity, $F_{\mathrm{lg}}$ is the interaction force between the liquid and the gas, $F_{\mathrm{lw}}$ is the friction force between the liquid and the conduit wall, $R$ is the gas constant (462 $\mathrm{J} \mathrm{kg}^{-1} \mathrm{~K}^{-1}$ for $\mathrm{H}_{2} \mathrm{O}$ gas), $T$ is the magma temperature, $n_{0}$ is the initial $\mathrm{H}_{2} \mathrm{O}$ content, and $s$ is the saturation constant $\left(4.11 \times 10^{-6} \mathrm{~Pa}^{-1 / 2}\right.$ for silicic magmas).

Equations (1) and (2) describe the mass conservations of the liquid and the gas respectively, and Eqs. (3) and (4) the momentum conservations of the liquid and the gas respectively. Equation (5) is the equation of state for the gas phase, and Eq. (6) represents the mass-flow-rate fraction of the gas when equilibrium gas exsolution on the basis of the solubility curve of $\mathrm{H}_{2} \mathrm{O}$ in a magma (Burnham and Davis, 1974) is assumed. We also assume that temperature change due to expansion is negligible because of the large heat capacity of the liquid magma; therefore, the energy equation is not solved.

The constitutive equation of $F_{\text {lw }}$ is given by the form for a Poiseuille flow of the liquid adjacent to the cylindrical conduit wall (Wilson et al., 1980):

$$
F_{1 \mathrm{w}}=\frac{8 \mu}{r_{\mathrm{c}}^{2}} u_{1}
$$

where $\mu$ is the magma viscosity and $r_{\mathrm{c}}$ is the conduit radius. Under the assumption that the vertical gas escape occurs on the basis of Darcy's law, the constitutive equation of $F_{\text {lg }}$ is given by

$$
F_{\mathrm{lg}}=\frac{\mu_{\mathrm{g}}}{k} \phi^{2}\left(u_{\mathrm{g}}-u_{\mathrm{l}}\right)
$$

where $\mu_{\mathrm{g}}$ is the gas viscosity (set to be $10^{-5} \mathrm{~Pa} \mathrm{~s}$ in this study) and $k$ is the permeability of magma. In the bubbly flow region, $F_{\mathrm{lg}}$ is given by $\frac{3 \mu}{r_{\mathrm{b}}^{2}} \phi(1-\phi)\left(u_{\mathrm{g}}-u_{\mathrm{l}}\right)$ where $r_{\mathrm{b}}$ is the bubble radius. For typical bubble sizes $(0.001-10 \mathrm{~mm})$ in silicic magma $\left(\mu>10^{5} \mathrm{Pas}\right)$, the relative velocity in this region is sufficiently small and the flow is essentially same as flow without a relative velocity difference (Kozono and Koyaguchi, 2009a).

In dome-forming eruptions, the inertia terms (the lefthand sides of Eqs. (3) and (4)) are negligibly small (e.g., Kozono and Koyaguchi, 2009a). Therefore, Eqs. (3) and (4) with the approximation of $\rho_{\mathrm{l}} \gg \rho_{\mathrm{g}}$ yield:

$$
-F_{\mathrm{lg}}+\phi F_{\mathrm{lw}}+\phi(1-\phi) \rho_{\mathrm{l}} g=0 .
$$

The first, second and third terms in the left-hand side of this equation represent the effects of the gas-liquid interaction force, the wall friction force and the gravitational load, respectively. This equation implies that the porosity of magma during dome-forming eruptions is controlled by a simple balance of these three effects.

In order to evaluate the relative importance of these three effects, we rewrite Eq. (9) using Eqs. (1), (2), (5), (7) and (8) as

$$
1-\frac{n \rho_{1} R T(1-\phi)}{(1-n) P \phi}+\varepsilon+\frac{1-\phi}{1-n} \theta=0
$$

where

$$
\varepsilon=\frac{8 \mu k}{\mu_{\mathrm{g}} r_{\mathrm{c}}^{2} \phi}
$$

and

$$
\theta=\frac{k \rho_{1}^{2} g(1-\phi)}{\mu_{\mathrm{g}} q \phi} .
$$

Here, the non-dimensional number $\varepsilon$ represents the ratio of effects of the wall friction force to the liquid-gas interaction force, and the non-dimensional number $\theta$ represents the ratio of effects of the gravitational load to the liquid-gas interaction force. On the basis of Eq. (10), we can calculate the porosity $\phi$ as a function of the magma properties such as the viscosity $\mu$ and the permeability $k$, the conduit radius $r_{\mathrm{c}}$, and the mass flow rate $q$ for a given pressure $P$.

Figure 2 is a diagram showing the relationships among $\varepsilon, \theta$ and $\phi$ for a given pressure on the basis of Eq. (10). The figure shows that the magnitude of $\phi$ decreases with increasing $\varepsilon$ or $\theta$. This tendency is explained in the following way. As $\varepsilon$ increases, the effect of the wall friction force increases (see Eq. (11)); as a result, the ascent of the liquid is suppressed, whereas the gas ascends easily. As $\theta$ increases, the effect of the liquid-gas interaction force decreases (see Eq. (12)), and allows the gas to separate from the dense liquid efficiently. These two effects promote gas escape from magma, leading to the decrease in $\phi$.

Figure 2 shows that $\phi$ depends on $\varepsilon$ alone for $\varepsilon \gg \theta$, and depends on $\theta$ alone for $\varepsilon \ll \theta$. From Eq. (10), we obtain the forms of $\phi$ in the limits of $\varepsilon \gg \theta$ (i.e., $\theta \rightarrow 0$ ) and $\varepsilon \ll \theta$ (i.e., $\varepsilon \rightarrow 0$ ) as

$$
\left.\phi\right|_{\theta \rightarrow 0}=\frac{A}{\varepsilon+A+1}
$$

and

$$
\left.\phi\right|_{\varepsilon \rightarrow 0}=\frac{1}{2}+\frac{(A+1)(1-n)}{2 \theta}
$$



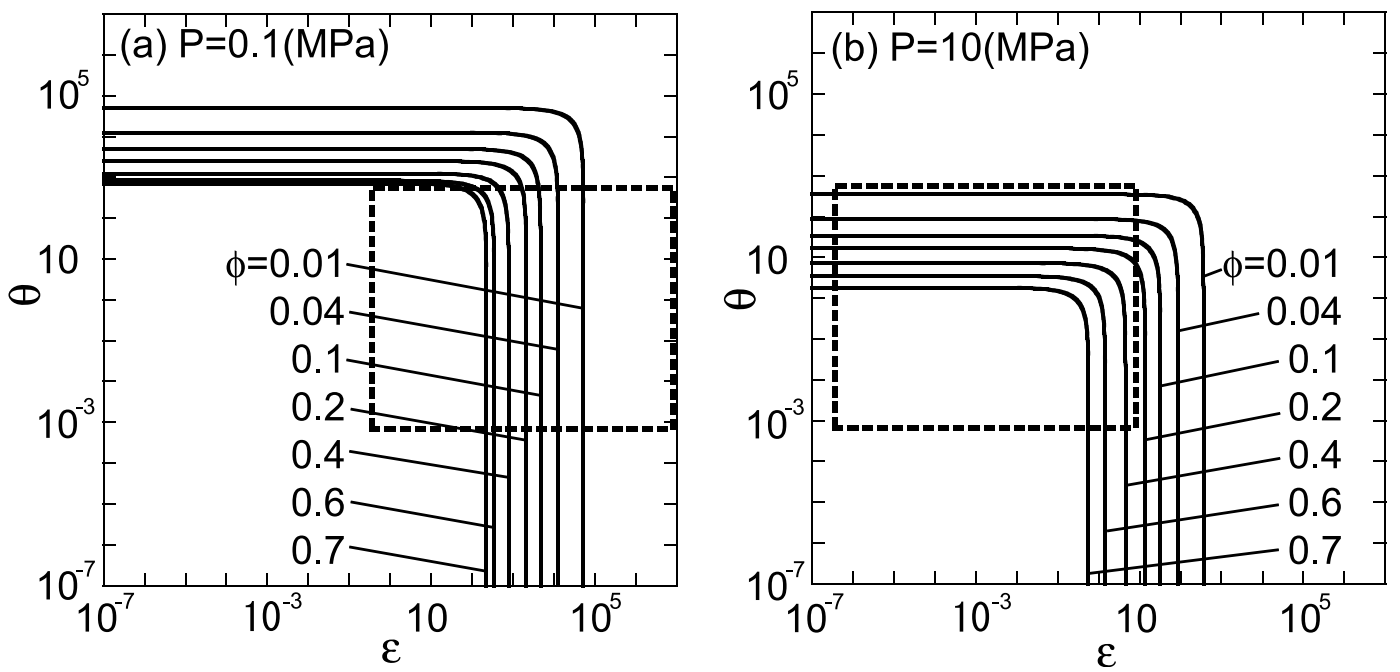

Fig. 2. Relationships among non-dimensional parameters $\varepsilon$ and $\theta$ and porosity $(\phi)$ for $n_{0}=0.04$ and $T=1123$ (K) on the basis of Eq. (10). (a) Results for $P=0.1(\mathrm{MPa})$; (b) results for $P=10(\mathrm{MPa})$. Possible ranges of $\varepsilon$ and $\theta$ estimated from typical values of $\mu, k, r_{\mathrm{c}}, q$ and $\phi$ for actual dome-forming eruptions $\left(\mu=10^{11}-10^{14} \mathrm{~Pa} \mathrm{~s}\right.$ for (a) and $10^{5}-10^{8} \mathrm{~Pa} \mathrm{~s}$ for (b), $k=10^{-14}-10^{-12} \mathrm{~m}^{2}, r_{\mathrm{c}}=10-50 \mathrm{~m}, q=0.1-10 \mathrm{~kg} \mathrm{~m}^{-2} \mathrm{~s}^{-1}$ and $\phi=0.1-0.8$ ) are also shown (dashed squares). The range of $\mu$ for (a) is estimated from the viscosities of lava domes under dry conditions (Kozono and Koyaguchi, 2009b); the range of $\mu$ for (b) is estimated to cover both the viscosities at the magma chamber (Kozono and Koyaguchi, 2009b) and the viscosity at $P=10(\mathrm{MPa})$ using Eq. (16). See Eqs. (11) and (12) for the definitions of $\varepsilon$ and $\theta$, respectively.

$$
-\sqrt{\left[\frac{1}{2}-\frac{(A+1)(1-n)}{2 \theta}\right]^{2}+\frac{1-n}{\theta}}
$$

respectively, where

$$
A=\frac{n \rho_{1} R T}{(1-n) P} .
$$

\section{Comparison with the Result Based on Eqs. (1)-} (8)

In the 1-dimensional steady conduit flow models, the porosity of magma is determined by solving the differential equations (i.e., Eqs. (1)-(8)) as a two-point boundary value problem (referred to as "DE-2BV"). The boundary condition at the bottom end of the conduit is that the pressure is equal to the pressure at the magma chamber and $u_{\mathrm{g}}=u_{\mathrm{l}}$, and the boundary condition at the vent is that the pressure is equal to the atmospheric pressure. The variations of physical quantities such as $\phi, u_{1}, u_{\mathrm{g}}$ and $P$ with depth throughout the conduit and the value of the mass flow rate $q$ are obtained such that the boundary conditions are satisfied. On the other hand, Eq. (10) provides an algebraic expression of $\phi$ for a given $\varepsilon, \theta$, and $P$. This formula cannot determine the value of $q$ as DE-2BV does, but determines the relationships among $\phi, \mu$, and $k$ at a given pressure when the value of $q$ is somehow known. Because Eq. (10) is valid for general forms of $\mu$ and $k$, it is useful for studying how $\phi$ varies as $\mu$ and $k$ change with depth in a complex way. In this section, we demonstrate that Eq. (10) can correctly estimate the porosity as a function of $P$ for realistic forms of $\mu$ and $k$ when the value of $q$ is given as a parameter.

We take into account the effects of dissolved $\mathrm{H}_{2} \mathrm{O}$ content and crystal content on the magma viscosity:

$$
\mu=\mu_{1}(c) f_{\mu}(\beta),
$$

where $\mu_{1}$ is the liquid viscosity expressed by a function of the mass fraction of dissolved water in the liquid $c$ (= $\left.s P^{1 / 2}\right)$, and $f_{\mu}(\beta)$ is a function that represents the influence of volume fraction of crystals $\beta$ on viscosity. The forms of $\mu_{1}(c)$ and $f_{\mu}(\beta)$ are determined from the models by Hess and Dingwell (1996) and Costa (2005), respectively. The increase in $\beta$ during magma ascent is assumed to be caused by crystallization of microlites. We can express the volume fraction of microlites of the groundmass $\beta_{\mathrm{mi}}$ as a function of $P$ using a power law fit for the experimental data of crystal growth kinetics for the 1995-1999 eruption of Soufrière Hills Volcano, Montserrat (Couch et al., 2003). In the fitting process, we use the data from the multiple decompression experiments shown in figure 8 of Couch et al. (2003) and assume that $\beta_{\mathrm{mi}}=0.5$ at $P=0.1 \mathrm{MPa}$ as a reference. As a consequence, $\beta$ is expressed by $\beta_{\mathrm{ph}}+$ $0.3361\left(10^{-6} P\right)^{-0.18955}\left(1-\beta_{\mathrm{ph}}\right)$ where $\beta_{\mathrm{ph}}$ is the volume fraction of phenocrysts. Because both $c$ and $\beta$ primarily depend on $P, \mu$ can be approximated by a function of $P$.

The permeability $k$ is expressed as a function of $\phi$ :

$$
k=k_{0} f_{k}(\phi),
$$

where $k_{0}$ is a magnitude-defining constant and $f_{k}(\phi)$ is a function that represents the influence of $\phi$ on the permeability. We tentatively assume that the values of $k_{0}$ and the form of $f_{k}(\phi)$ are determined from the model of $k-\phi$ relationship for effusive products by Mueller et al. (2005); $k_{0}=1 \times 10^{-17}\left(\mathrm{~m}^{2}\right)$, and $f_{k}(\phi)=(100 \phi)^{3}$.

Figure 3(a, b, d, e) shows the results, based on DE-2BV and Eq. (10), of the changes in porosity and velocities as a function of $P$ during magma ascent from the magma chamber to the vent, in which Eqs. (16) and (17) are used for $\mu$ and $k$, respectively. In order to obtain the value of $\theta$ in Eq. (10), we used the value of $q$ determined from DE-2BV. As magma ascends and decompresses, the increase in the porosity is suppressed (Fig. 3(a,d)) owing to efficient gas escape (i.e., the increase in the relative velocity between the gas and the liquid; Fig. 3(b, e)), leading to the flow 

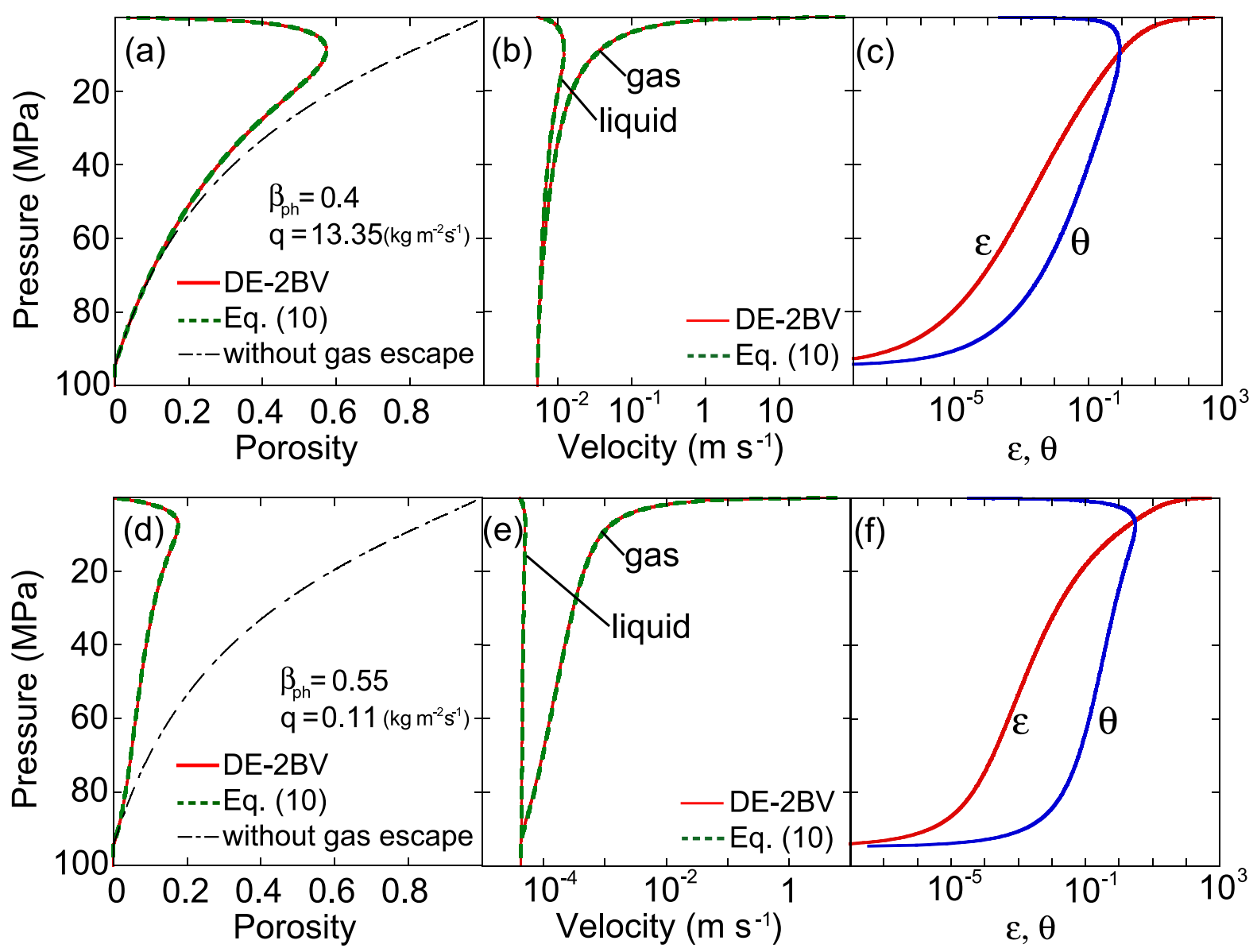

Fig. 3. Representative results of variations of porosity (a, d), velocities of the liquid and the gas (b, e), and the parameters $\varepsilon$ and $\theta$ (c, $\mathrm{f}$ ) as a function of $P$ during magma ascent from the magma chamber to the vent. The parameters used for the calculation are $r_{\mathrm{c}}=10 \mathrm{~m}, T=1123 \mathrm{~K}, n_{0}=0.04$, $L=4000 \mathrm{~m}$ and $P_{0}=100 \mathrm{MPa}$ where $L$ is conduit length and $P_{0}$ is pressure at the magma chamber. (a, b, c) Results for $\beta_{\mathrm{ph}}=0.4$ and $q=13.35$ $\mathrm{kg} \mathrm{m}^{-2} \mathrm{~s}^{-1} ;(\mathrm{d}, \mathrm{e}, \mathrm{f})$ results for $\beta_{\mathrm{ph}}=0.55$ and $q=0.11 \mathrm{~kg} \mathrm{~m}^{-2} \mathrm{~s}^{-1}$. In (a), (b), (d) and (e), red and green curves show the results based on DE-2BV and Eq. (10), respectively. The results of $u_{1}$ and $u_{\mathrm{g}}$ as a function of $P$ based on Eq. (10) in (b) and (e) are obtained by substituting $\phi(P)$ into Eqs. (1) and (2). The result for the flow without gas escape is also shown in (a) and (d) (dashed and dotted curve).

reaching the vent with a low porosity. The result of Eq. (10) compares well with that of DE-2BV in a quantitative sense and also successfully captures the complex features of the porosity profile in conduits (Fig. 3(a,d)).

The above results show that if the value of $q$ is known, Eq. (10) can correctly determine the porosity as a function of $P$ for realistic forms of $\mu$ and $k$. In actual eruptions, the value of $q$ can be estimated from field observations. In addition, we know that $P$ at the surface is atmospheric and that $P$ in the subsurface region is greater than atmospheric. Therefore, we can evaluate how the porosity at the surface or in the subsurface region is controlled by the variations of $\mu$ and $k$ on the basis of Eq. (10).

\section{Geological Implications}

During dome-forming eruptions, magma porosity changes through the competing effects of the magma vesiculation and the gas escape from magma. According to field observations, the porosity of lava domes typically ranges from 0 to 0.5 (e.g., Melnik and Sparks, 2002; Kueppers et al., 2005; Mueller et al., 2005). On the other hand, Clarke et al. (2007) showed that the porosity in the subsurface region where the pressure is higher than about $10 \mathrm{MPa}$ can be as large as $0.5-0.7$, as was the case for the pre-explosion (dome growth) state of the 1997 events in Soufrière Hills Volcano, Montserrat (SHV). We discuss the mechanism for these observed porosity distributions to be generated on the basis of our simple formula, Eq. (10).

Figure 2 describes how the porosity near the surface $(P=0.1 \mathrm{MPa})$ and that in the subsurface region $(P=$ $10 \mathrm{MPa}$ ) depend on $\varepsilon$ and $\theta$ on the basis of Eq. (10). In this diagram, possible ranges of $\varepsilon$ and $\theta$ estimated from the typical values of $\mu, k, r_{\mathrm{c}}$ and $q$ for actual dome-forming eruptions are shown. Generally, the value of $\varepsilon$ increases dramatically with decreasing $P$ in response to the increase in $\mu$ (Fig. 3(c)). This effect is taken into consideration for the possible range of $\varepsilon$ in Fig. 2. At pressures near the surface $(P=0.1 \mathrm{MPa})$, the porosity depends on $\varepsilon$ and is unaffected by $\theta$ (Fig. 2(a)). On the other hand, at pressures in the subsurface region ( $P=10 \mathrm{MPa}$ ), the porosity depends on $\theta$ rather than on $\varepsilon$ (Fig. 2(b)).

The above results show that the increase in the magma viscosity plays an important role in explaining the low porosity (close to zero) near the surface observed in lava domes. The porosity near the surface decreases with increasing $\varepsilon$ (Fig. 2(a)). Considering that the permeability decreases with decreasing porosity (e.g., Mueller et al., 2005) and that there is not a large variation of $r_{\mathrm{c}}$, the increase in 

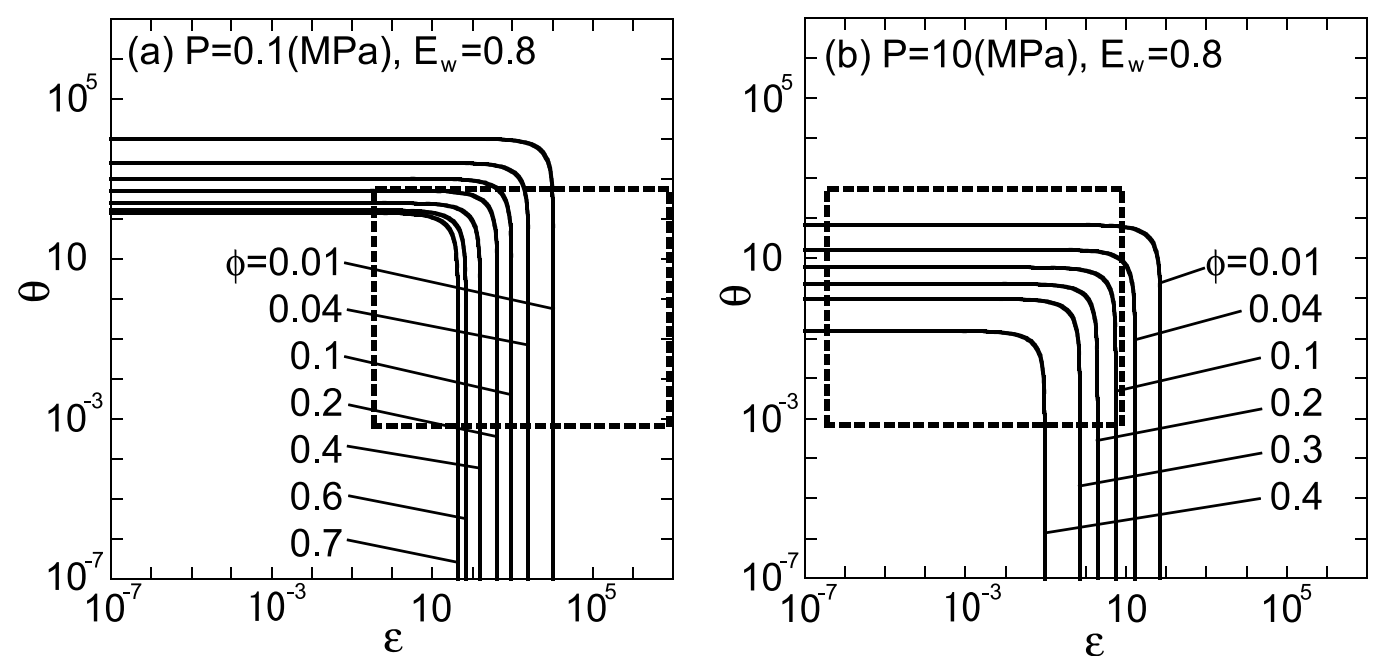

Fig. 4. Relationships among $\varepsilon, \theta$ and $\phi$ in the case where the effect of lateral gas escape from magma is taken into account on the basis of Eq. (A.3) for $E_{\mathrm{w}}=0.8$. Dashed squares are as in Fig. 2 .

$\varepsilon$ is ascribed to the increase in the magma viscosity (see Eq. (11)). The viscosity drastically increases in the region near the surface because of volatile exsolution and crystallization. As a result, the ascent of the liquid is suppressed owing to large wall friction force, whereas the gas ascends easily (i.e., efficient gas escape). For example, when the viscosity near the surface increases up to $10^{14} \mathrm{~Pa} \mathrm{~s}, \varepsilon$ can become larger than $10^{3}$, which leads to a porosity smaller than 0.2 (Fig. 2(a)). The porosity near the surface remains low even when the mass flow rate is high, because the porosity in this region is insensitive to $\theta$ (Fig. 2(a)).

In contrast, the porosity in the subsurface region is sensitive to $\theta$ (Fig. 2(b)). This indicates that the increase in the mass flow rate plays a major role in explaining the high porosity in the subsurface region estimated for SHV (0.50.7). Considering again the permeability-porosity relationship, the increase in mass flow rate results in a decrease in $\theta$ (see Eq. (12)), which in turn leads to an increase in subsurface porosity (see Fig. 2(b)). For the possible ranges of $\varepsilon$ and $\theta$ in Fig. 2(b), the porosity $\phi$ is larger than 0.5 when $\theta$ is smaller than about 1 . In the case of $k \sim 10^{-12} \mathrm{~m}^{2}$ (the value for SHV when $\phi=0.5-0.7$; Melnik and Sparks, 2002), the mass flow rate $q$ must exceed $5 \mathrm{~kg} \mathrm{~m}^{-2} \mathrm{~s}^{-1}$ for $\theta<1$. (e.g., compare Fig. 3(a-c) with Fig. 3(d-f)). This estimation is consistent with the observation that $q$ at the pre-explosion state of the 1997 events in SHV reached about $28 \mathrm{~kg} \mathrm{~m}^{-2}$ $\mathrm{s}^{-1}$ (Sparks et al., 1998). We suggest that the high flow rate immediately prior to the explosive activity induced the increase in the subsurface porosity.

Equation (10) can be extended to the case where the effect of lateral gas escape from magma (e.g., Jaupart and Allegre, 1991; Woods and Koyaguchi, 1994; Diller et al., 2006) is taken into account (see Appendix). When this effect is considered, the isopleths of the porosity in Fig. 2 shift to the left and downward (Fig. 4), which indicates that the porosity diminishes for relatively low $\varepsilon$ or $\theta$. However, even if the lateral gas escape occurs efficiently (the ratio of the lateral to vertical gas flow rates $E_{\mathrm{w}}$ is 0.8 ; Fig. 4), the present conclusion that porosity near the surface depends on $\varepsilon$ (i.e., $\mu$ ) and that porosity in the subsurface region depends on $\theta$ (i.e., $q$ ) is unchanged. Equation (10) can also be extended to the case where conduit geometry varies (de'Michieli Vitturi et al., 2008) by taking into account the variation of $r_{\mathrm{c}}$ in Eq. (10).

In conclusion, we have derived a simple formula for calculating the porosity of magma in dome-forming eruptions as a function of mass flow rate, magma properties such as the viscosity and the permeability, and pressure. On the basis of this formula, we have shown that the increase in the magma viscosity due to volatile exsolution and crystallization near the surface plays a key role in the formation of a porosity distribution in dome-forming eruptions. The porosity near the surface approaches 0 owing to the high magma viscosity regardless of the magnitude of the mass flow rate, whereas the subsurface porosity increases to more than 0.5 with increasing mass flow rate. In order to understand the mechanism of the porosity change in dome-forming eruptions, we need to quantitatively evaluate complex effects of the magma properties such as degassinginduced crystallization (e.g., Melnik and Sparks, 2005), non-Newtonian rheology of crystal-bearing magma (e.g., Caricchi et al., 2007), and various relationships between permeability and porosity (e.g., Eichelberger et al., 1986; Takeuchi et al., 2005). The simple formula obtained in this paper (Eq. (10)) will be useful for systematically analyzing the relationship between these complex effects of the magma properties and the conduit flow dynamics.

Acknowledgments. We thank Sebastian Mueller and Wim Degruyter for insightful comments in improving an earlier version of the manuscript. We are grateful to Alain Burgisser and Shigeo Yoshida for helpful reviews and suggestions that greatly improved the manuscript. This work was supported by Grant-inAid for Scientific Research (B) (No. 18340130, 21340123) and for Young Scientist (B) (No. 21740322) from MEXT, and the Earthquake Research Institute cooperative research program.

\section{Appendix A. The Effect of Lateral Gas Escape}

In this appendix we show how the simple formula (Eq. (10)) is extended when the effect of lateral gas escape from magma to the conduit wall is taken into account. Here, 
we introduce a parameter expressing the degree of the lateral gas escape as:

$$
E_{\mathrm{w}}=\frac{q_{\mathrm{w}}}{n q},
$$

where $q_{\mathrm{w}}$ is the flow rate of the gas escaping laterally. This parameter represents the ratio of the lateral gas flow rate to the vertical gas flow rate. Using $E_{\mathrm{w}}$, the mass conservation equation of the gas (Eq. (2)) is rewritten by

$$
\rho_{\mathrm{g}} u_{\mathrm{g}} \phi=n q\left(1-E_{\mathrm{w}}\right) \text {. }
$$

From Eqs. (1), (5), (7), (8), (9) and (A.2), we obtain the formula for calculating the porosity in the case where the lateral gas escape is considered:

$$
1-\frac{n \rho_{1} R T(1-\phi)}{(1-n) P \phi}\left(1-E_{\mathrm{w}}\right)+\varepsilon+\frac{1-\phi}{1-n} \theta=0 .
$$

\section{References}

Burnham, C. and N. Davis, The role of $\mathrm{H}_{2} \mathrm{O}$ in silicate melts: II. Thermodynamic and phase relations in system $\mathrm{NaAlSi}_{3} \mathrm{O}_{8}-\mathrm{H}_{2} \mathrm{O}$ to 10 kilobars, $700^{\circ} \mathrm{C}$ to $1100^{\circ} \mathrm{C}, \mathrm{Am} . J . S c i ., 274,902-940,1974$.

Caricchi, L., L. Burlini, P. Ulmer, T. Gerya, M. Vassalli, and P. Papale, Non-Newtonian rheology of crystal-bearing magmas and implications for magma ascent dynamics, Earth Planet. Sci. Lett., 264, 402-419, 2007.

Clarke, A., S. Stephens, R. Teasdale, R. Sparks, and K. Diller, Petrologic constraints on the decompression history of magma prior to Vulcanian explosions at the Soufrière Hills Volcano, Montserrat, J. Volcanol. Geotherm. Res., 161, 261-274, 2007.

Costa, A., Viscosity of high crystal content melts: dependence on solid fraction, Geophys. Res. Lett., 32, L22308, 2005.

Couch, S., R. Sparks, and M. Carroll, The kinetics of degassing-induced crystallization at Soufrière Hills Volcano, Montserrat, J. Petrol., 44, 1477-1502, 2003.

de'Michieli Vitturi, M., A. Clarke, A. Neri, and B. Voight, Effects of conduit geometry on magma ascent dynamics in dome-forming eruptions, Earth Planet. Sci. Lett., 272, 567-578, 2008.

Diller, K., A. Clarke, B. Voight, and A. Neri, Mechanisms of conduit plug formation: Implications for vulcanian explosions, Geophys. Res. Lett., 33, L20302, 2006.

Eichelberger, J., C. Carrigan, H. Westrich, and R. Price, Non-explosive silicic volcanism, Nature, 323, 598-602, 1986.
Hess, K. U. and D. B. Dingwell, Viscosities of hydrous leucogranitic melts: A non-Arrhenian model, Am. Mineral., 81, 1297-1300, 1996.

Jaupart, C. and C. Allegre, Gas content, eruption rate and instabilities of eruption regime in silicic volcanoes, Earth Planet. Sci. Lett., 102, 413 429, 1991.

Kozono, T. and T. Koyaguchi, Effects of relative motion between gas and liquid on 1-dimensional steady flow in silicic volcanic conduits: 1. an analytical method, J. Volcanol. Geotherm. Res., 180, 21-36, 2009a.

Kozono, T. and T. Koyaguchi, Effects of relative motion between gas and liquid on 1-dimensional steady flow in silicic volcanic conduits: 2 . origin of diversity of eruption styles, J. Volcanol. Geotherm. Res., 180, 37-49, 2009b.

Kueppers, U., B. Scheu, O. Spieler, and D. Dingwell, Field-based density measurements as tool to identify preeruption dome structure: set-up and first results from Unzen volcano, Japan, J. Volcanol. Geotherm. Res., 141, 65-75, 2005.

Melnik, O. and R. Sparks, Nonlinear dynamics of lava dome extrusion, Nature, 402, 37-41, 1999.

Melnik, O. and R. Sparks, Dynamics of magma ascent and lava extrusion at Soufrière Hills Volcano, Montserrat, in The Eruption of Soufrière Hills Volcano, Montserrat, from 1995 to 1999, edited by T. H. Druitt and B. P. Kokelaar, 645 pp, Geological Society, London, Memoirs, 21, 153-171, 2002.

Melnik, O. and R. Sparks, Controls on conduit magma flow dynamics during lava dome building eruptions, J. Geophys. Res., 110, B02209, 2005.

Mueller, S., O. Melnik, O. Spieler, B. Scheu, and D. Dingwell, Permeability and degassing of dome lavas undergoing rapid decompression: An experimental determination, Bull. Volcanol., 67, 526-538, 2005.

Sparks, R., S. Young, J. Barclay, E. Calder, P. Cole, B. Darroux, M. Davies, T. Druitt, C. Harford, R. Herd, and others, Magma production and growth of the lava dome of the Soufriére Hills Volcano, Montserrat, West Indies: November 1995 to December 1997, Geophys. Res. Lett., 25, 3421-3424, 1998.

Takeuchi, S., S. Nakashima, A. Tomiya, and H. Shinohara, Experimental constraints on the low gas permeability of vesicular magma during decompression, Geophys. Res. Lett., 32, L10312, 2005.

Wilson, L., R. Sparks, and G. Walker, Explosive volcanic eruptions: IV. The control of magma properties and conduit geometry on eruption column behavior, Geophys. J. R. Astron. Soc., 63, 117-148, 1980.

Woods, A. and T. Koyaguchi, Transitions between explosive and effusive eruptions of silicic magmas, Nature, 370, 641-644, 1994.

T. Kozono (e-mail: kozono@bosai.go.jp) and T. Koyaguchi 